\title{
Contribution to the Control of the Power Switches of DC-DC Converters with two stages of a Photovoltaic System
}

\author{
Mohammed Faysal Yaden ${ }^{1 *}$, El Hadi Baghaz ${ }^{2}$, Mustapha Melhaoui ${ }^{3}$, and Kamal Hirech ${ }^{4}$ \\ ${ }^{1}$ ENSAM, Moulay Ismaïl University, Meknes, Morocco \\ ${ }^{2}$ Faculty of Sciences, Chouaib Doukkali University, El Jdida, Morocco \\ ${ }^{3}$ Faculty of Sciences \& Technics, Cadi Ayyad University, Marrakech, Morocco \\ ${ }^{4}$ Faculty of Sciences, Mohammed I University, Oujda, Morocco
}

\begin{abstract}
The work presented in this article proposes the design and the realization of a PWM controller, which allows the control of the power switches of DC-DC converters of discrete two-stage photovoltaic systems in series. The method employed is based on the use of two drivers by exploiting their functionalities in order to improve and control the two power switches of the discretized photovoltaic system. The proposed technique is validated by experimentation on a photovoltaic system, the upper stage of which can request a floating voltage on the MOSFET drain of up to $30 \mathrm{~V}$. the studied PV installation is equipped by a protection circuit block for protect the PV equipments in the event of poor connection or deterioration of elements in system blocks. The simulations and the experiments showed a good functioning of the control unit which ensured: An amplitude of the PWM signals large enough to control the power switches, optimal system operation regardless of load and weather changes and good efficiency, and protection of the installation in the event of malfunction.
\end{abstract}

\section{Introduction}

Currently, most of the electric power generation is produced from non-renewable and non-clean fossil resources. However, the latter have a very slow regeneration time which leads to their exhaustion in nature [1].

In addition, the impact of the energy consumption of these resources on the environment, gives rise to significant greenhouse gas emissions playing a major role in the level of global warming and the increase in pollution [2].

To this end, renewable energy sources, in their multiple forms: hydroelectric, solar photovoltaic, biomass, deep geothermal energy, compensate for the energy shortage while limiting the negative impact on the environment with virtually varied and inexhaustible resources [3].

Statistical and forecasting studies therefore show that PV energy could meet humanity's high demand for electricity. Indeed, photovoltaic energy [4], produced by photovoltaic cells, based on the direct transformation of light energy from the sun into electricity, is distinguished from other renewable energies by its significant energy potential. Indeed, the total amount of energy received by solar radiation at ground level for a week exceeds the energy that can be produced by all of the world's reserves of oil, coal, gas and uranium [5]. Towards an improvement in the performance of a discretized photovoltaic (PV) system [6,7], numerous studies and works have shown the interest of multi-stage PV systems in series in stand-alone installations $[3,8,9]$ and injected into the electricity grid [10,11]. In these power applications, the floating voltages at the output of DC-DC converters [12], influence the shape of the PWM signal generated by the control of the stage converter switches $[13,14,15,16]$. The establishment of a specific controller seems necessary to avoid the malfunction of the DC / DC converter and to minimize the power losses of the PV system [6,3,10]. Most of the work encountered in the literature does not deal in depth with the operation of the converter stages, in particular the control of the power switches of DC / DC converters $[17,18,19]$. In this context, we are carrying out research allowing the improvement of the performance of PV systems in order to improve energy production, system reliability and therefore the efficiency of DC / DC converters. Thus, allowing their application in standalone PV installations. In this work, we propose the design, the realization, and the experimental results of a discretized PV system, optimized with two stages in series. Special care is drawn to:

- Optimizing the operation by a specific MPPT control adapted to a discretized system

- providing a reliable control technique for the power switches of the DC / DC converters of the two stages.

- Protection of operation and equipments in the PV installation.

In the first section, we present the operation of the main blocks of the two-stage discretized photovoltaic system, and in the second section we validate the experimental results obtained by comparing them with the simulated ones.

\footnotetext{
* Corresponding author: y.faysal@yahoo.fr
} 


\section{Global photovoltaic system}

\subsection{Structure of the system}

The overall structure of the discretized PV system which is the subject of our work is represented in Fig. 1. The different blocks of this system are:

- PV generators formed by PV panels in Upper and Lower stages.

- A load that can be batteries or a DC resistor.

- Two adaptation stages (low and high), formed by Boost DC/DC converters.

- Two protection blocks

- A digital MPPT control adapted to a discretized PV system, which generates two PWM signals and based on the use of a Microcontroller (PIC) according to an algorithm that considers the specific technical characteristics of the PV generators used.

- A Switch Control Block (SCB).

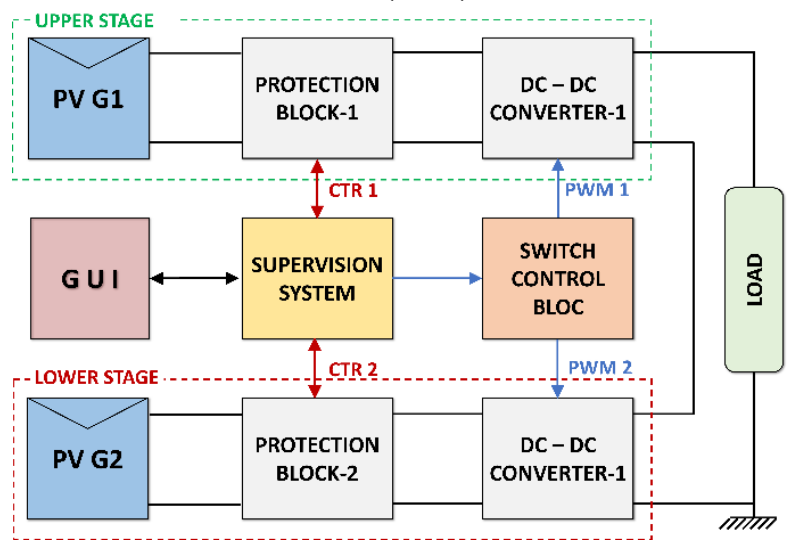

Fig. 1. Structure of the PV installation consisting of two floors (the upper and the lower stages).

\subsection{MPPT control}

The control of the entire PV system is managed by a single microcontroller. The system is designed to acquire the electrical quantities and to perform the MPPT algorithm to control the two-level PV structure. Therefore, the control system generates two PWM signals (PWM 1 and PWM 2 signals) (Fig. 2) to control simultaneously, via the SCB block, the power switches of the two stages of the system for the smooth operation of the PV installation. The algorithm (Fig. 3) implemented on the microcontroller is based on improved incremental conductance algorithm, on which we specified and included a specific PV voltage range [17-20] to enhance its performance. This range represents the area where photovoltaic panels operate under optimum conditions regardless of weather conditions (illumination and temperature) (Fig. 4).

The MPPT algorithm depends on the slope of the P-V curve, which can be affected by the solar irradiation level and the load. Besides tracking the MPP by searching the peak of the $\mathrm{P}-\mathrm{V}$ curve, we also set the algorithm to use the evolution of PV optimal voltage range to set the appropriate duty cycle of PWM signal controlling the DC/DC converter. Therefore, in our case, the MPPT algorithm is more focused on the area where the PV voltage is inside the optimal voltage ranges (13V-16V) (Fig. 3) [17]. Finally, the algorithm functioning is set to control the two duty cycles of the PWM signals (PWM 1 and PWM 2). These signals control the power switches of our system in order to operate around the operating point of each PV panels to ensure that the PV system generates maximum power at all times and avoiding the divergence problem of the PV operation.

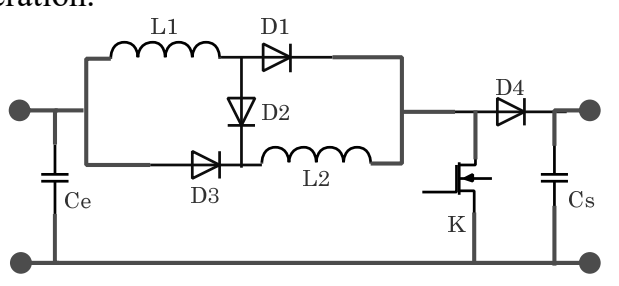

Fig. 2: The electrical circuit of the BOOST converter used in this study

After acquiring the electrical quantities of the PV generator, the MPPT algorithm (Fig. 3) locates the position of the generator voltage in relation to the range between [Vmin, Vmax].

If the voltage is outside the range [Vmin, Vmax], the algorithm will bring it back into this range with a large increment step of around 0.05 , then it will look for the maximum power point.

Otherwise, if the voltage is in the range [Vmin, Vmax], the algorithm will precisely seek the maximum power point with a small increment step of around 0.01 .

The increase or decrease in the duty cycle that controls the DC-DC converter is based on the state of evolution of the PV generator parameters as well as the increment step.

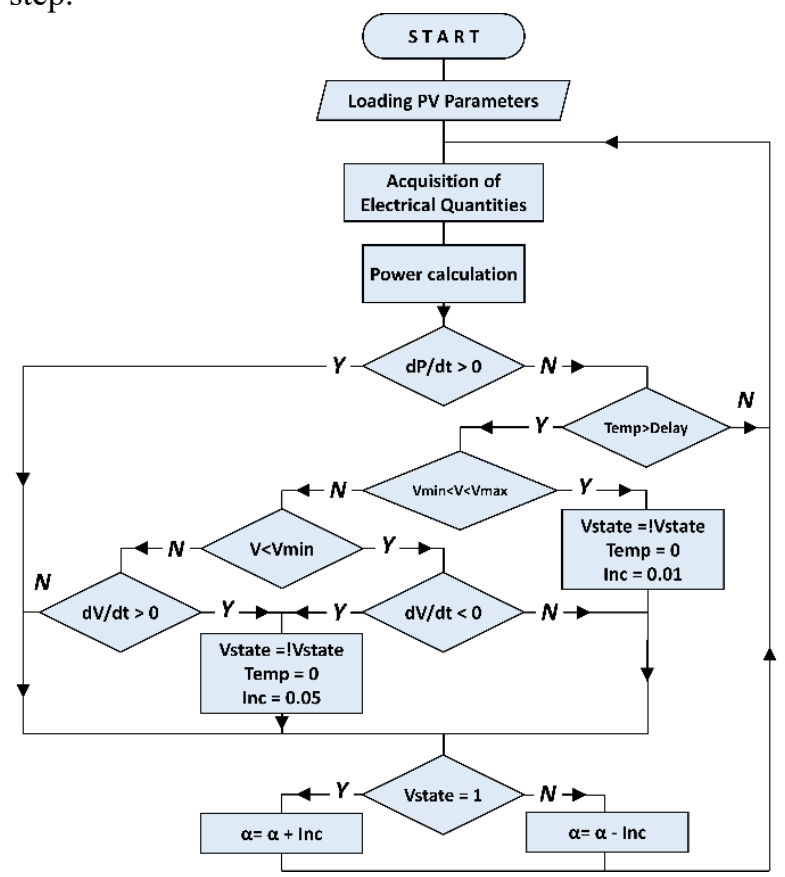

Fig 3: MPPT algorithm implemented on the microcontroller 


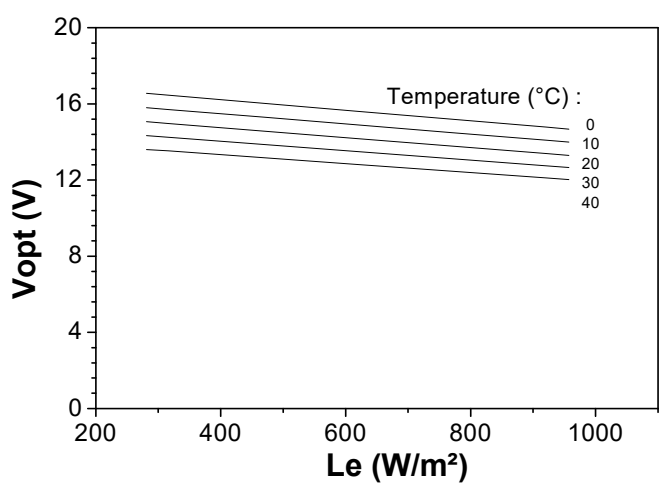

Fig. 4: Optimal voltages of PV panels depending on temperature and lighting.

\subsection{The switch control Block SCB}

The PV system studied is formed by two DC/DC converters in series, two protection blocks, two PV generators and the power switches control system which requires two PWM signals (PWM 1 and PWM 2), that have respectively an amplitude of $12 \mathrm{~V}$ and $35 \mathrm{~V}$. Since the microcontroller can only generates two PWM signals with an amplitude of $5 \mathrm{~V}$, then the use of the SCB block is necessary to control the power switches of the PV system. Using the drivers shown in Fig. 5, we propose the structure of the SCB as follows:

The bottom circuit (Fig. 5.A), requires one Driver (Driver 1), which provides PWM1 signal:

$\mathrm{HO}=\mathrm{VCC}+\mathrm{VS}$

Where, VCC represents the power supply of the driver (12V).

Since the PWM signal is varying and VS is connected to the ground $(0 \mathrm{~V})$, then PWM 1 signal is also varying with an amplitude of the order of VCC:

$\mathrm{HO}=\mathrm{VCC} \approx 12 \mathrm{~V}$

The upper circuit (Fig. 5.B) based on the configuration of the internal structure of the driver used [21]. It requires the combination of two identical drivers as shown in Fig. 4. Consequently, we obtain two PWM signals (signals PWM 21 and PWM 2):

$\mathrm{HO} 1=\mathrm{VCC} 1+\mathrm{VS} 1$

Where, VCC1 represents the power supply of the Driver $(20 \mathrm{~V})$.

We have VS1 pin connected to ground. So:

$$
\begin{aligned}
\mathrm{HO} 1 & =\mathrm{VCC} 1 \\
\mathrm{HO} 2 & =\mathrm{VCC} 2+\mathrm{VS} 2 \\
& =\mathrm{VCC} 2+\mathrm{HO} 1
\end{aligned}
$$

Since PWM signals and HO1 are varying and VS2 is connected to HO1 then PWM 2_1 signal and PWM are also varying within an amplitude respectively of $20 \mathrm{~V}$ and $40 \mathrm{~V}$.

All these analyzes allow us to conclude that the SCB block of Fig. 4 generates signals that can control the opening and the closing of the power switches of the two DC / DC converters.

- PWM1 signal, rectangular with an amplitude of $12 \mathrm{~V}$,

- PWM2_1 signal, rectangular, with an amplitude of $20 \mathrm{~V}$,

- PWM2 signal, rectangular with an amplitude of $40 \mathrm{~V}$.

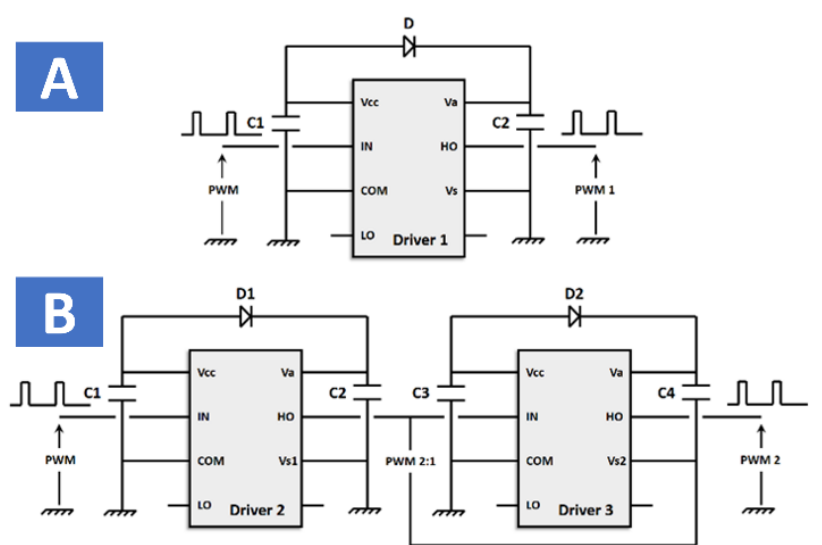

Fig 5: Switches Control Block diagram (SCB).

\section{Experimental results and discussions}

\subsection{Experimental procedure}

The system studied is constituted by:

- 2 Photovoltaics generators (PVG1 et PVG2)

- Two DC/DC boost converter in series used for the discretized architecture.

- Digital MPPT control implemented in a microcontroller (Arduino uno) according to the algorithm of Fig. 2,

- A Switch control block (SCB) which generates

- Resistor DC load,

- Meteorological station based on acquisition of irradiance and temperature values.

\subsection{Results discussion}

\subsubsection{Specifications}

In order to validate experimentally the operation of the PV system, we have realized the following PV system with two stages:

- Two double inductance DC / DC Boost converter in series used for the discretized PV architecture are designed to operate under $10 \mathrm{kHz}$ of frequency with a maximum power of $150 \mathrm{~W}$ and a current of $12 \mathrm{~A}$,

- Two protection control system controlled by an ON/OFF signal (Ctrl1 and Ctrl2) generated by the microcontroller with $5 \mathrm{~V}$ voltage

- Hill Climbing MPPT control, that generate 2 PWM signals with a voltage around $5 \mathrm{~V}$. the first one (PWM1) is amplified by the driver 1 (Fig. 4-A) to achieve 12V (PWM1) for a good control of the BOOST1 switch, and the second one is amplified by the second and the 3rd drivers (Fig. 4-B) to achieve $40 \mathrm{~V}$ for a good control of the BOOST2 (Upper stage) switch.

- Resistive load with variable value.

- A Human machine Interface for acquisition of the various electrical values. 


\subsubsection{Operation of the SCB block}

The typical experimental results, for an illumination of $800 \mathrm{~W} / \mathrm{m}^{2}$, of the obtained PWM-1and PWM-2 signals are shown in Fig. 6. The waveforms of these signals show:

- Rectangular signals with a frequency of $20 \mathrm{kHz}$ and a duty cycle about 0.6 ,

- PWM 1 and PWM 2 signals with an amplitude of $12 \mathrm{~V}$ and $40 \mathrm{~V}$ respectively.

These results are in very good agreement with those simulated and fixed by the specifications. As a result, the SCB can control perfectly the two power switches (Mosfet1 and Mosfet2) of the Boost DC/DC converters (Upper and Lower), connected in series, for a frequency of $10 \mathrm{kHz}$.

Usually in DC-DC converters integrating N-type MOSFETs, it is impossible to cascade them because the control voltage is very high and its value depends on the number of stages, the technique used in this work therefore addresses this problem. and improve the control of converters.
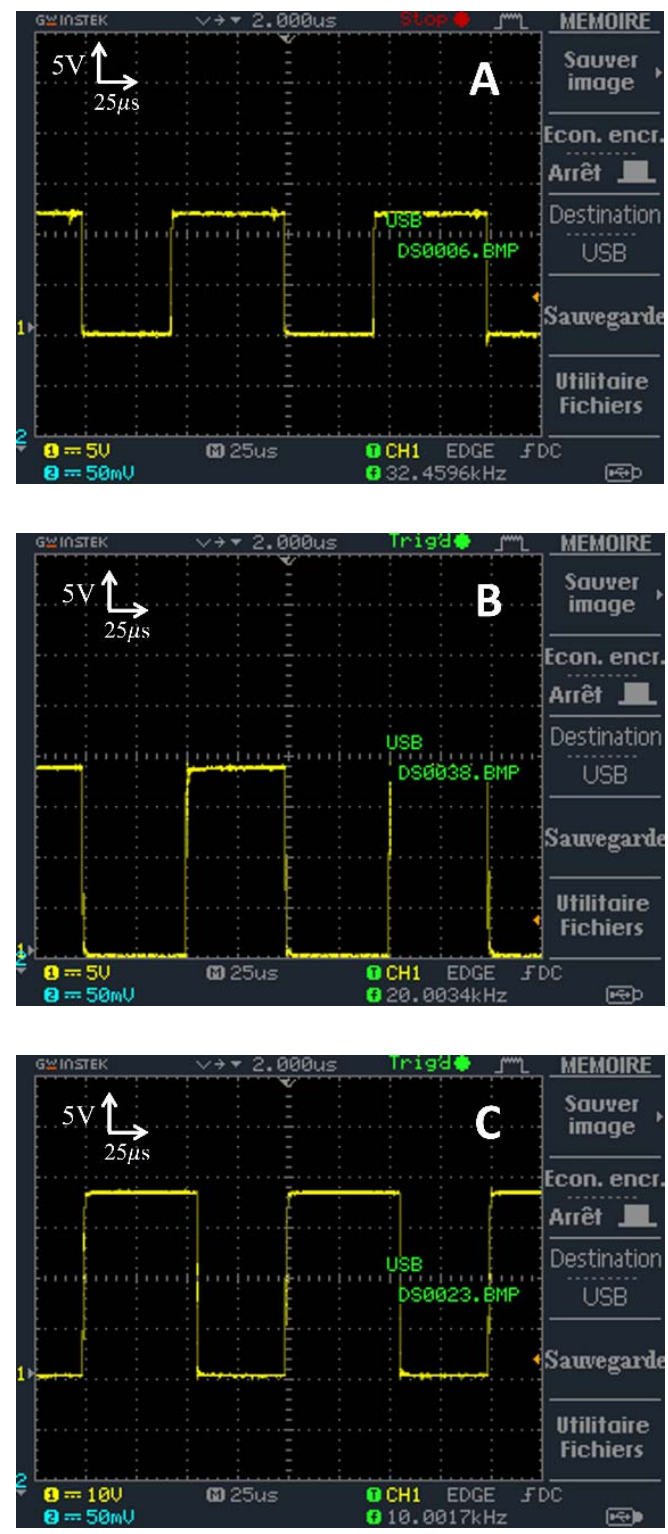

Fig. 6: Waveforms of the PWM 1 (A), PWM 2_1 (B) and PWM 2 (C) signals.

\section{Conclusion}

The paper presents an analysis of the control of the power switches of two-stage DC / DC converters of the Photovoltaic system. By relying on the internal structure of the drivers, we have made available a specific SPB power unit making it possible to generate two PWM signals of suitable shapes to control the switches of the stages of the system having a floating voltage (output of the first stage) at around $30 \mathrm{~V}$. All the experimental results and simulations obtained show that:

The PWM signals are characterized by an amplitude largely sufficient to control the power switches,

The simulation and experience of the electrical quantities of each block of the PV system are in phase,

The operation of each adaptation stage and of the complete PV system was optimal,

The efficiency of each stage is in the order of $88 \%$.

From the results obtained, we have shown that the control of the two power switches, on opening and closing, considers the floating voltage of the DC / DC converter of the lower stage. Consequently, the structure of the specific power block (SPB) proposed during this work is approved and its use in multi-stage photovoltaic systems is largely justified.

\section{Appendix}

\begin{tabular}{|c|c|}
\hline Term & Abbreviation \\
\hline Pulse-Width Modulation & PWM \\
\hline Direct Current to Direct Current converter & DC-DC \\
\hline Maximum Power Point Tracker & MPPT \\
\hline Switch Control Block & SCB \\
\hline Specific Power Block & SPB \\
\hline Photovoltaics Generators & PV G1-2 \\
\hline Graphical User Interface & GUI \\
\hline ON/OFF Control Signal & CTR1-2 \\
\hline Input Voltage State & VSTATE \\
\hline
\end{tabular}

\section{References}

1. JM Beér, High Efficiency Electric Power Generation; The Environmental Role, Progress in Energy and Combustion Science, 2007, Elsevier

2. C.S. Snyder, T.W. Bruulsema, T.L. Jensen, P.E. Fixen, Review of greenhouse gas emissions from crop production systems and fertilizer management effects, Agriculture, Ecosystems and Environment, 2009 - Elsevier 
3. C Koroneos, T Spachos, N Moussiopoulos - Exergy analysis of renewable energy sources, Renewable energy, 2003 - Elsevier

4. $\mathrm{R}$ De Leone, $\mathrm{M}$ Pietrini, A Giovannelli Photovoltaic energy production forecast using support vector regression, Neural Computing and Applications, 2015 - Springer

5. Limites des ressources naturelles, Conférence AFTP CFE IFP, Enerdata 3 juin 2009.

6. DT Cotfas, AM Deaconu, PA Cotfas, Application of successive discretization algorithm for determining photovoltaic cells parameters, Energy conversion and management- Elsevier, 2019

7. N. Subramanian, P. Prasanth, R. Srinivasan, R. R. Subhesh, R. Seyezhai, Analysis and Experimentation of Soft Switched Interleaved Boost Converter for Photovoltaic Applications, IJE TRANSACTIONS A: Basics Vol. 28, No. 10 (October 2015) 1469-1475

8. Tinton Dwi Atmaja, Façade and Rooftop PV Installation Strategy for Building Integrated Photo Voltaic Application, Energy Procedia,Vol 32, 2013, pp. 105-114.

9. Carlos Carvalho, José Lameiro, Nuno Paulino, Guilherme Lavareda., A Step-up $\mu$-Power Converter for Solar Energy Harvesting Applications, using Hill Climbing Maximum Power Point Tracking. In Circuits and Systems (ISCAS), 2011 IEEE International Symposium on (pp. 1924-1927).

10. V. Salas, E. Olıas, M. Alonso, F. Chenlo. Overview of the legislation of DC injection in the network for low voltage small grid-connected PV systems in Spain and other countries. Renewable and Sustainable Energy Reviews 12 (2008) 575-583.

11. Yang Du, Dylan Dah-Chuan Lu, Battery-integrated boost converter utilizing distributed MPPT configuration for photovoltaic systems, Solar Energy, vol. 85, 2011, pp. 1992-2002.

12. ABDELSALAM, Ahmed K., MASSOUD, Ahmed M., AHMED, Shehab, High-performance adaptive perturb and observe MPPT technique for photovoltaic-based microgrids. IEEE Transactions on Power Electronics, 2011, vol. 26, no 4, p. 10101021.

13. B. Haihong, Z. Weiping, C. Bing, Control Simulation and Experimental Verification of Maximum Power Point Tracking Based on RTLAB, IJE TRANSACTIONS A: Basics Vol. 29, No. 10 (October 2016) 1372-1379

14. Yaow-Ming CHEN. Multi-input DC/DC converter based on the multiwinding transformer for renewable energy applications. IEEE transactions on industry applications, 2002, vol. 38, no 4, p. 1096-1104.

15. Y. Zhang, M. Rodriguez, D. Maksimovic. 100 $\mathrm{MHz}, 20 \mathrm{~V}, 90 \%$ efficient synchronous Buck converter with integrated gate driver, in Proc. IEEE Energy Convers. Congr. Expo., 2014.
16. Yuanzhe Zhang, Miguel Rodriguez and Dragan Maksimovic. High-Frequency Integrated Gate Drivers for Half-Bridge GaN Power Stage, IEEE TRANSACTIONS ON POWER ELECTRONICS, VOL. 29, NO. 5, MAY 2014.

17. AM Deaconu, DT Cotfas, PA Cotfas - Calculation of Seven Photovoltaic Cells Parameters Using Parallelized Successive Discretization Algorithm, International Journal of Photoenergy, 2020

18. A Dehghanzadeh, G Farahani, $\mathrm{H}$ Vahedi, K AlHaddad, Model predictive control design for DCDC converters applied to a photovoltaic system, International Journal of Electrical Power \& Energy Systems - Elsevier, Vol. 103, December 2018, Pages 537-544.

19. M.Vimala, C.B.Venkataramanam, High Performance Model Preditive Technique For Mpptgrid-Tied Pv System Using Chopper, International Journal of Engineering Development and Research (IJEDR) | Volume 5, 2017, Issue 2 | ISSN: 2321-9939.

20. Ho-sung Kim, Jong-Hyun Kim, Byung-Duk Min, Dong-Wook Yoo, Hee-Je Kim., A highly efficient PV system using a series connection of DC-DC converter output with a photovoltaic panel, Renewable Energy, vol 34, 2009,pp. 2432-2436

21. Jianhui Wong n, YunSengLim, JunHuatTang, EzraMorris. Grid-connected photovoltaic system in Malaysia: A review on voltage issues. Renewable and Sustainable Energy Reviews 29 (2014) 535545 . 